\title{
A Metastatic Jejunal Tumor from Squamous Cell Carcinoma of the Lung Found in an Intestinal Perforation
}

\author{
Takayuki Tanaka $^{a}$ Shigeki Minami ${ }^{a}$ Ryuji Tsutsumi ${ }^{d}$ \\ Takashi Azuma $^{\mathrm{b}}$ Shigetoshi Matsuo ${ }^{\mathrm{b}}$ Kuniko Abe ${ }^{\mathrm{c}}$

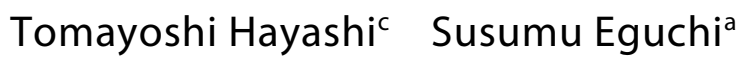

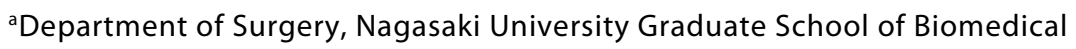
Sciences, Nagasaki, bDepartment of Surgery, Nagasaki Prefecture Shimabara Hospital, Shimabara, 'Department of Pathology, Nagasaki University Hospital, Nagasaki, and dDepartment of Surgery, National Health Insurance Hirado Municipal Hospital, Hirado, Japan

\section{Key Words}

Intestinal metastasis · Peritonitis · Lung cancer

\begin{abstract}
An 85-year-old male with advanced squamous cell carcinoma of the lung, who was diagnosed about 10 years prior to his current presentation, suddenly complained of abdominal pain and underwent an abdominal computed tomography scan, which revealed free air and massive ascites. He was admitted to our hospital for acute peritonitis and emergency surgery was performed. During the surgical procedure, a perforation of the jejunum was diagnosed and repaired. He was diagnosed to have a metastatic tumor originating from a squamous cell carcinoma of the lung. He improved and was transferred to the former hospital on the 27 th postoperative day. Jejunal metastasis from squamous cell carcinoma of the lung is rare, and the prognosis of peritonitis due to a perforated intestinal metastasis from lung cancer is poor. There have been 10 reports of jejunal metastasis of squamous cell carcinoma of the lung reported in Japan between 2000 and 2011. Therefore, when patients with advanced lung cancer present with acute abdomen, it is necessary to keep in mind the possibility of a gastrointestinal metastatic tumor.
\end{abstract}




\section{Introduction}

Lung cancer has a high rate of metastasis, and the malignant potential is high. The most common metastatic sites are the other lung (50\%), liver (37\%), adrenal gland (31\%), bone (29\%), kidneys (18\%), and brain (12\%), but the frequency of metastasis to the digestive tract is rare $(2.8-8.8 \%)$. Furthermore, in various reports, the rate of metastatic intestinal tumors from lung cancer was about $0.1-3 \%$. The most common histological type resulting in metastasis is large cell carcinoma, followed by adenocarcinoma, small cell carcinoma, and squamous cell carcinoma. A small intestinal metastatic tumor can cause various symptoms, such as obstruction, malabsorption, hemorrhage, and perforation. Therefore, emergency operation may be needed when such symptoms occur. However, the prognosis is extremely poor when intestinal metastasis is found at the condition of perforation. We herein report a rare case of a metastatic jejunal tumor that originated from squamous cell carcinoma of the lung and which was found when the patient developed peritonitis and was treated successfully with surgery.

\section{Case Report}

The present case was an 85-year-old male patient with a previous history of squamous cell carcinoma of the lung (T1N0M0 stage Ib) which was diagnosed about 10 years prior to his current presentation. He had received stereotactic irradiation for 3 months, and for 2 years thereafter he remained stable. During a follow-up examination, it was found that the lung tumor had grown and that he had also developed a metastatic bone tumor (T4N1M1 stage IV). He received best supportive care and was admitted to a hospital for pain control. However, while in the hospital, he experienced sudden abdominal pain. He was transferred to our hospital with acute peritonitis. At the time of admission, the patient was $151 \mathrm{~cm}$ tall, weighted $43 \mathrm{~kg}$, and his BMI was $18.9 \mathrm{~kg} / \mathrm{m}^{2}$. His blood pressure was $126 / 76 \mathrm{~mm} \mathrm{Hg}$ with a heart rate of 89 beats/min, a body temperature of $37.5^{\circ} \mathrm{C}$, and a $\mathrm{SpO}_{2}$ of $98 \%$ on room air. Physical examination revealed slight anemia on conjunctival examination, marked abdominal tenderness, and peritoneal irritation. Laboratory tests revealed a WBC count of 7,500 cells $/ \mathrm{m}^{3}$, a hemoglobin level of $8.7 \mathrm{~g} / \mathrm{dl}$, a platelet level of $30.0 \times 10^{4} \mathrm{cells} / \mathrm{m}^{3}$, an albumin level of $3.4 \mathrm{~g} / \mathrm{dl}$, a BUN level of $28.3 \mathrm{mg} / \mathrm{dl}$, a creatinine level of $0.60 \mathrm{mg} / \mathrm{dl}$, and a CRP level of $12.21 \mathrm{mg} / \mathrm{dl}$. His transaminase level was normal. In the coagulation test, the prothrombin time was $88.0 \%$ (INR: 1.01). In the blood gas test, the results were indicative of alkalosis, with a $\mathrm{pH}$ of 7.522, a $\mathrm{PaCO}_{2}$ of 37.1 , a $\mathrm{PaO}_{2}$ of $78.8, \mathrm{a} \mathrm{HCO}_{3}$ of 30.3, and a BE of 7.0. A chest X-ray revealed a large tumor in the right lower lung and multiple small nodules in both lungs. A chest computed tomography (CT) scan revealed the same findings as the chest X-ray. An abdominal CT scan revealed free air and massive ascites in the Douglas fossa (fig. 1). An upper gastrointestinal series with water-soluble contrast media showed no obvious areas of perforation. Although the site of perforation was not identified, he was diagnosed with acute peritonitis with gastrointestinal perforation and underwent emergency surgery. During the surgical procedure, a large amount of dirty ascites was found. A perforation was discovered about $70 \mathrm{~cm}$ inside the jejunum from Treitz's ligament (fig. 2). An intestinal resection of approximately $40 \mathrm{~cm}$ was performed. The intraperitoneal cavity was washed with $6,000 \mathrm{ml}$ saline solution and a functional end-to-end anastomosis was performed. After the operation the patient improved gradually. He was transferred to the former hospital on the 27th postoperative day. However, he died about 2 months after having been transferred. The pathological diagnosis of the resected specimen was a metastatic jejunal tumor from a squamous cell carcinoma of the lung (fig. 3 ).

\section{Discussion}

Lung cancer has a high rate of metastasis, and the malignant potential is high. The most common metastatic sites are the other lung (50\%), liver (37\%), adrenal gland (31\%), bone (29\%), kidneys (18\%), and brain (12\%), but the frequency of metastasis to the 
digestive tract is rare $(2.8-8.8 \%)$ [1-3]. Furthermore, in various reports, the rate of metastatic intestinal tumors from lung cancer was about $0.1-3 \%[3,4]$. Metastatic intestinal tumors from lung cancer present with various symptoms. Takeyoshi et al. [5] reported that the clinical presentation of a metastatic intestinal tumor is most commonly a perforation $(35.9 \%)$, followed by stenosis $(27 \%)$, intussusception $(21.8 \%)$, and melena (15.4\%) [5-8]. The present case was found to have a jejunal perforation, and emergency operation was necessary.

In a histological examination of gastrointestinal metastatic tumors from lung cancer, Ryo et al. [9] reported that metastasis of lung cancer to the digestive tract (excluding the esophagus) was confirmed by surgery or autopsy in 30 of 1,635 lung cancer patients during a 17 -year period, and that the most common histological type of lung cancer was large cell carcinoma (3.7\%), followed by adenocarcinoma (2.4\%), small cell carcinoma (1.7\%), and squamous cell carcinoma (0.7\%). In the present case, the histological type was squamous cell carcinoma.

The prognosis of metastatic intestinal tumor perforation is especially poor. Metastatic intestinal tumor from lung cancer was demonstrated to occur more often in males than in females, and at a mean age of 64.5 years [10]. The 1-year survival rate in patients who underwent surgery for the perforation was $12 \%$ [11]. While the $50 \%$ cumulative survival rate for obstruction was about 3 months, that for perforation was about 1.7 months [11]. Since the prognosis of the lung cancer itself is poor and peritonitis further decreases the patient's condition, it was thought that the prognosis of patients who underwent surgery for a metastatic intestinal tumor was especially poor $[1-3,5]$. In the present case, the patient died about 2 months after he was transferred to his former hospital (about 3 months after surgery).

Perforation due a metastatic intestinal tumor is thought to be caused by ischemia of the intestinal wall resulting from a blood or tumor thrombus, the necrosis of the intestinal wall as a result of chemotherapy, an increase in the intestinal pressure induced by obstruction, and so on [12]. In the present case, the symptom of obstruction was not present and the patient was not treated with chemotherapy. The mechanism responsible for his perforation was therefore thought to be the following: First, tumor cells from the lung cancer metastasized to the small intestine via the bloodstream. Second, the tumor cells became established in the submucosal layer and started to grow in the new location. Finally, the center of the tumor became relatively ischemic, causing perforation.

Because of the advances in chemotherapy and supportive care, the survival of lung cancer patients has been increasing. Therefore, it is necessary to pay attention to the symptoms indicative of a metastatic intestinal tumor, such as obstruction, abdominal pain, melena, nausea and so on. If such symptoms appear, it is thought to be possible to improve a patient's quality of life by locating the metastatic sites with positron emission tomography (PET) and treating them appropriately, including with surgery when indicated. Recently, various reports have shown the usefulness of PET [13-15]. If we could effectively use PET in such cases, we might be able to more accurately predict the presence of intestinal metastatic tumors.

In conclusion, we experienced a rare case of perforation of an intestinal metastatic tumor caused by lung cancer. To our knowledge, the prognosis of metastatic intestinal tumors from lung cancer is very poor, and the survival rate is extremely low. Therefore, 
when patients with advanced lung cancer develop an acute abdomen, it is necessary to keep in mind the possibility of a gastrointestinal metastatic tumor and to appropriately diagnose and treat the acute abdomen.
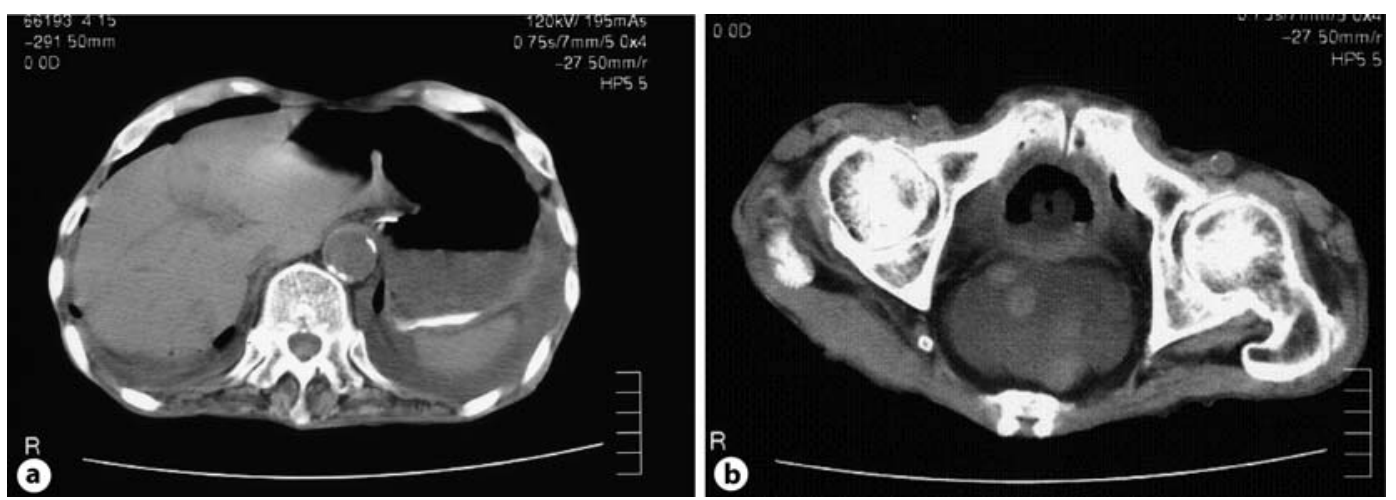

Fig. 1. CT images. a CT scan of the abdomen. Free air was revealed in the upper abdominal cavity and massive ascites in the Douglas fossa. $\mathbf{b}$ CT scan of pelvis. Massive ascites was shown.

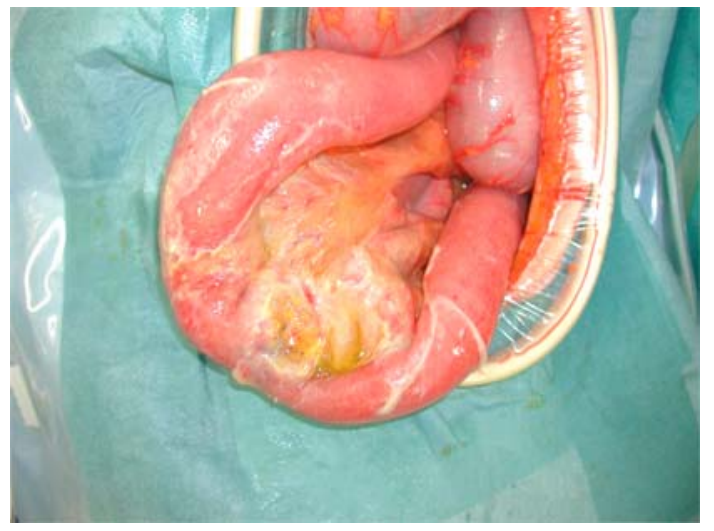

Fig. 2. Surgical findings. A perforation located $70 \mathrm{~cm}$ from Treitz's ligament was revealed. 


\begin{tabular}{|c|c|c|c|}
\hline $\begin{array}{r}\text { Case Reports in } \\
\text { Gastroenterology }\end{array}$ & $\begin{array}{l}\text { Case Rep Gastroenterol 2011;5:636-641 } \\
\text { DOI: } 10.1159 / 000334426\end{array}$ & $\begin{array}{l}\text { Published online: } \\
\text { November 6, } 2011\end{array}$ & $\begin{array}{l}\text { (c) } 2011 \text { S. Karger AG, Basel } \\
\text { ISSN 1662-0631 } \\
\text { www.karger.com/crg }\end{array}$ \\
\hline
\end{tabular}
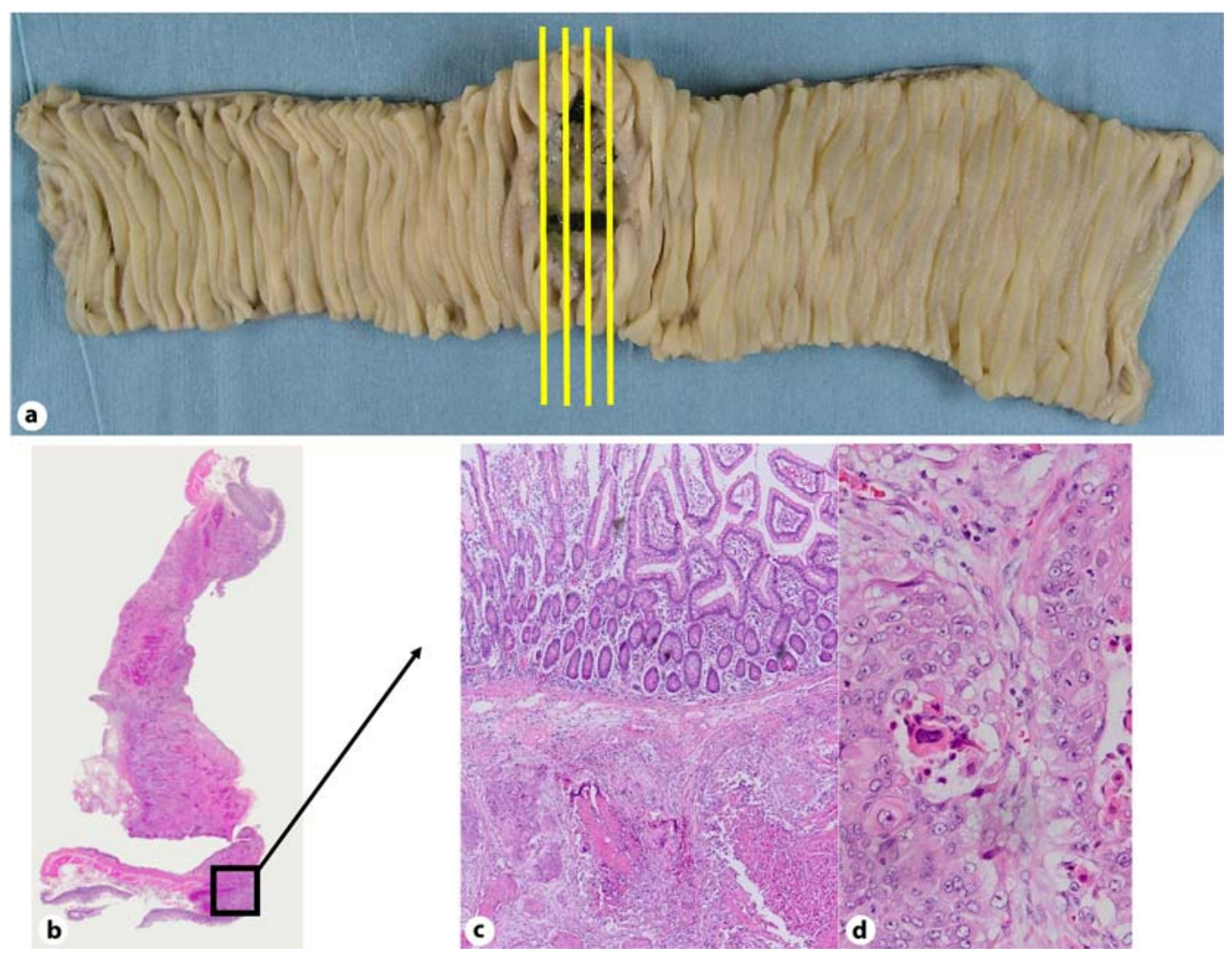

Fig. 3. Macroscopic and histological findings of the perforation site. a The specimen of the intestine containing the ulceration in the center. Squamous cell cancer was recognized in the small intestinal wall with hematoxylin at $1 \times(\mathbf{b})$ and $10 \times$ magnification $(\mathbf{c})$ and in the blood vessels at $40 \times$ magnification $(\mathbf{d})$.

\section{References}

1 Stenbygaard LE, Sorensen JB, Larsen H, Dombernowsky P: Metastatic pattern in non-resectable non-small cell lung cancer. Acta Oncol 1999;38:993-998.

2 Ochsner A, DeBakey M: Significance of metastasis in primary carcinoma of the lung. J Thorac Surg 1942;11:357-387.

3 McNeill PM, Wagman LD, Neifeld JP: Small bowel metastases from primary carcinoma of the lung. Cancer 1987;59:1486-1489.

4 Yang CJ, Hwang JJ, Kang WY, et al: Gastro-intestinal metastasis of primary lung carcinoma: clinical presentations and outcome. Lung Cancer 2006;54:319-323.

5 Takeyoshi I, Suzuki S, Ishikawa H, Ishikawa J, Sekine T, Suda Y, Uehara T: A case of multiple metastases of lung cancer, with cumulative study from the literature (in Japanese with English abstract). Nihon Rinsyou Geka Gakkai Zasshi (J Jpn Surg Assoc) 1990;51:91-97.

6 Leidich RB, Rudolph LE: Small bowel perforation secondary to metastatic lung carcinoma. Ann Surg 1981;193:67-69.

7 Berger A, Cellier C, Daniel C, et al: Small bowel metastases from primary carcinoma of the lung: clinical findings and outcome. Am J Gastroenterol 1999;94:1884-1887.

8 Garwood RA, Sawyer MD, Ledesma EJ, Foley E, Claridge JA: A case and review of bowel perforation secondary to metastatic lung cancer. Am Surg 2005;71:110-116.

-9 Ryo H, Sakai H, Ikeda T, et al: Gastrointestinal metastasis from lung cancer (in Japanese with English abstract). Nihon Kyobu Shikkan Gakkai Zasshi (Jpn J Thorac Surg) 1996;34:968-972. 
10 Nakagawa K, Yasumitsu T, Kotake Y, Fukuhara K, Ueshita S, Ogawa T: Seven operated cases of metastasis to the small intestine from lung cancer and a review of the Japanese literature (in Japanese with English abstract). Haigan (Lung Cancer) 1996;36:319-324.

11 Narikiyo M, Boku S, Nakatani K, Nakano H: A case of acute peritonitis due to perforated metastatic lesion of small intestine from lung cancer (in Japanese). Nihon Fukubu Kyukyu Igakukai Zasshi (Jpn J Abdom Emerg Med) 1997;17:1081-1085.

12 Ise N, Kotanagi H, Morii M, et al: Small bowel perforation caused by metastasis from an extra-abdominal malignancy: report of three cases. Surg Today 2001;31:358-362.

13 Hustinx R: PET imaging in assessing gastrointestinal tumors. Radiol Clin North Am 2004;42:1123-1139.

14 Kelly RF, Tran T, Holmstrom A, Murar J, Segurola RJ Jr: Accuracy and cost-effectiveness of [18F]-2-fluorodeoxy-D-glucose-positron emission tomography scan in potentially resectable non-small lung cancer. Chest 2004;125:1413-1423.

15 Shiono S, Masaoka T, Sato T, Yanagawa N: Positron emission tomography (PET)-computed tomography (CT) suggesting small intestinal metastasis from lung cancer: report of a case (in Japanese with English abstract). Kyobu Geka (Thorac Surg) 2006;59:426-429. 